\title{
Palladium Catalysts Based on Porous Aromatic Frameworks, Modified with Ethanolamino-Groups, for Hydrogenation of Alkynes, Alkenes and Dienes
}

\author{
Leonid Kulikov $^{1}{ }^{10}$, Maria Kalinina ${ }^{1}$, Daria Makeeva ${ }^{1}$, Anton Maximov ${ }^{1,2}$, Yulia Kardasheva ${ }^{1}$, \\ Maria Terenina ${ }^{1}$ and Eduard Karakhanov ${ }^{1, *}$ \\ 1 Department of Chemistry, Lomonosov Moscow State University, 119234 Moscow, Russia; \\ mailforleonid@mail.ru (L.K.); kalmary@yandex.ru (M.K.); d-makeeva95@yandex.ru (D.M.); \\ max@ips.ac.ru (A.M.); yuskard@petrol.chem.msu.ru (Y.K.); tereninam@petrol.chem.msu.ru (M.T.) \\ 2 Topchiev Institute of Petrochemical Synthesis, 119234 Moscow, Russia \\ * Correspondence: kar@petrol.chem.msu.ru; Tel.: +7-495-939-5377
}

Received: 28 August 2020; Accepted: 22 September 2020; Published: 24 September 2020

\begin{abstract}
The current work describes an attempt to synthesize hybrid materials combining porous aromatic frameworks (PAFs) and dendrimers and use them to obtain novel highly active and selective palladium catalysts. PAFs are carbon porous materials with rigid aromatic structure and high stability, and the dendrimers are macromolecules which can effectively stabilize metal nanoparticles and tune their activity in catalytic reactions. Two porous aromatic frameworks, PAF-20 and PAF-30, are modified step-by-step with diethanolamine and hydroxyl groups at the ends of which are replaced by new diethanolamine molecules. Then, palladium nanoparticles are applied to the synthesized materials. Properties of the obtained materials and catalysts are investigated using X-ray photoelectron spectroscopy, transmission electron microscopy, solid state nuclear magnetic resonance spectroscopy, low temperature $\mathrm{N}_{2}$ adsorption and elemental analysis. The resulting catalysts are successfully applied as an efficient and recyclable catalyst for selective hydrogenation of alkynes to alkenes at very high (up to 90,000) substrate/Pd ratios.
\end{abstract}

Keywords: hydrogenation; heterogeneous catalysts; palladium; porous polymers; amines

\section{Introduction}

Palladium is one of the most widespread metals used in the selective hydrogenation of unsaturated compounds [1-3]. It is commonly used in a form of nanoparticles, for this process, whose high surface area provides a large number of available active sites per unit area. This leads to greater reactivity of the nanoparticles than with bulk palladium [4]. Changes in the size of particles, their morphology and distribution significantly affect their catalytic properties. However, unstabilized metal nanoparticles (NPs) are prone to aggregation, which leads to the formation of thermodynamically stable large particles with lower catalytic activity [5]. The main method to avoid aggregation of NPs is the use of encapsulating ligands and polymers or porous materials [6-11].

One of the most effective supports for metal nanoparticles are dendrimers-regular, three-dimensional, spherically symmetric macromolecules. Since dendrimers have interior voids of nanometer dimensions, they can hold nanoparticles of suitable sizes, which can fit into those voids [12]. Encapsulation of metals in a structure of dendrimers allows for control of the size of the nanoparticles and provides for their uniform distribution [13]. Strong coordination of the chelating nitrogen-containing groups with metal prevents NPs from leaching and agglomerating during reaction, thus providing outstanding stability. However, the use of dendrimer-stabilized nanoparticles is limited 
due to difficulties, connected to their separation from the reaction mixtures and time-consuming synthesis, which includes multistage purification [14].

These disadvantages may be overcome using one of two possible approaches. The first includes the covalent linking of dendrimer macromolecules using different bi- and tri-functional agents $[15,16]$. The second implies the attachment of dendrimers or dendrons to the surface of organic or inorganic insoluble supports. The main examples of such carriers are $\mathrm{SiO}_{2}$ (both amorphous and mesoporous) $[9,17]$ multiwall carbon nanotubes, or cross-linked polymer resins, such as polystyrenes [18], polythiophenes [19], or polyvinylpyridines [20]. The development of such hybrid materials is promising for the field of hydrogenation, due to their high activity and stability, immense selectivity, and easy recyclability.

Due to high values of specific surface area, developed porosity, and a variety of methods for the synthesis and modification of the structure, mesoporous materials and polymers have found wide application in the stabilization of nanoparticles [21-27]. One of these materials are porous aromatic frameworks (PAF) - polymers with a rigid structure consisting of aromatic rings connected to each other [28]. Their aromatic nature provides thermal stability and the possibility for facile introduction of functional groups, as well as additional stabilization of palladium nanoparticles. Modification of the polymer structure with various functional groups allows improvement of characteristics of the resulting catalyst significantly to increase its stability, to control activity, and selectivity [29-36]. All these properties make porous aromatic frameworks promising supports for metal nanoparticles. The incorporation of coordination electron-donating groups in the material is regarded as an especially efficient method to stabilize active catalytic species [27,36-46].

Materials with nitrogen and oxygen functionalities, such as amine and hydroxyl groups, have a high affinity for metal ions [47]. Porous organic polymers with a high nitrogen and oxygen content have a high potential for the uptake of metal ions or the immobilization of metal nanoparticles [18,48-52]. Such features, and their resulting applications in heterogeneous catalysis, are the main driving force behind the design and synthesis of porous organic frameworks with electron-donating groups. Here, we study palladium catalysts based on mesoporous aromatic frameworks modified with diethanolamine in a hydrogenation of different unsaturated compounds.

\section{Results and Discussion}

\subsection{Synthesis and Characterization of Supports}

Porous aromatic frameworks (PAF), PAF-20 and PAF-30, were synthesized according to the method described by Yuan Y. et al. [53] from tetrakis-(p-bromophenyl)methane and 1,4-phenylenediboronic acid or 4,4'-biphenyldiboronic acid. Consequently, PAF-20 and PAF-30 differed in the number of benzene rings between $\mathrm{sp}^{3}$ carbon atoms in the nodes of the frameworks: PAF-20 had three benzene rings, and PAF-30 had four rings. Thus, PAF-20 typically had a smaller pore size, but a larger surface area compared to PAF-30 [24]. Subsequent modification of PAF structure with chloromethyl groups and diethanolamino groups was performed using methods by Gangadharan. D. et al. [54] and Lu.W. et al. [55] (Scheme 1). To determine the structural features of the structure of the obtained materials, they were studied using solid state nuclear magnetic resonance (NMR) spectroscopy, low-temperature $\mathrm{N}_{2}$ adsorption and elemental analysis. 


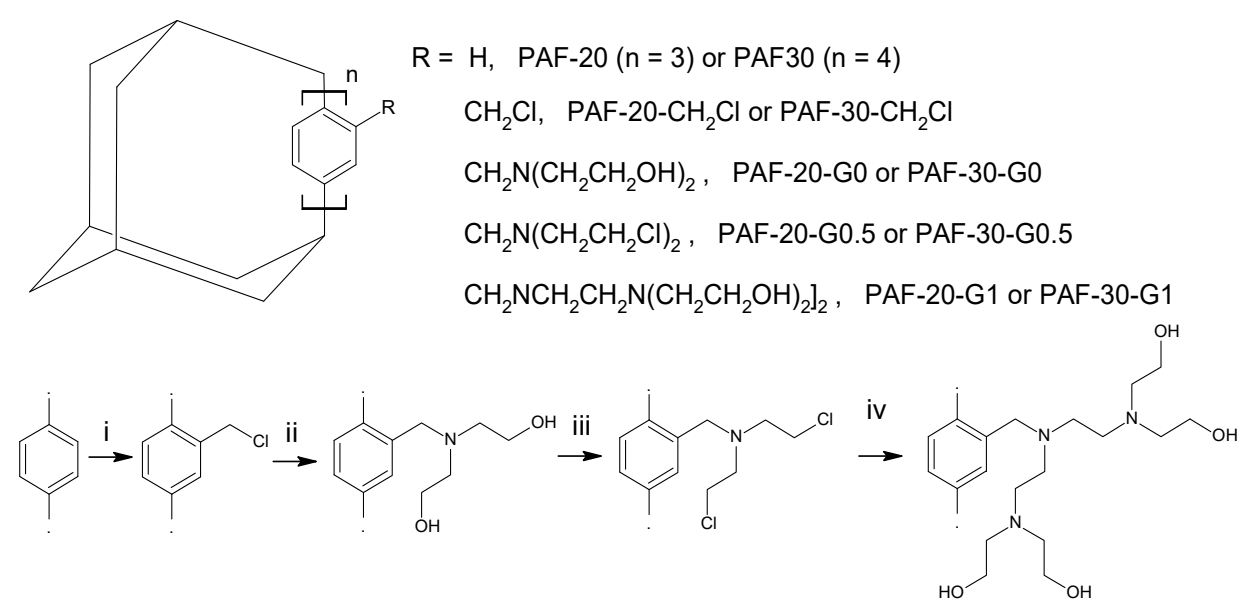

Scheme 1. Modification of PAF-20 and PAF-30. Reagents: (i) $\mathrm{CH}_{2} \mathrm{O}, \mathrm{HCl}, \mathrm{P}_{2} \mathrm{O}_{5}, \mathrm{AcOH}$, (ii) diethanolamine, dioxane, (iii) $\mathrm{SOCl}_{2}$, dioxane, (iv) $\mathrm{NH}(\mathrm{EtOH})_{2}$, dioxane.

Figure 1 shows the solid-state cross polarization-magic angle spinning (CP-MAS) ${ }^{13} \mathrm{C}$ NMR spectra for PAF-based materials. All spectra contained typical for PAF signals in the region of 125-145 ppm for $\mathrm{sp}^{2}$-hybridized carbon atoms of aromatic rings and, at $63 \mathrm{ppm}$, corresponded to $\mathrm{sp}^{3}$-hybridized carbon atoms in the center of tetraphenylmethane units. After modification with chloromethyl groups, a new signal belonging to the $-\mathrm{CH}_{2} \mathrm{Cl}$ group appeared at $44 \mathrm{ppm}$, which was consistent with published data $[56,57]$. Replacing the chlorine atom in $-\mathrm{CH}_{2} \mathrm{Cl}$ with an ethanolamine group reduced the intensity of this peak due to screening of the carbon atom by branched ethanolamine groups and shifted its position from $44 \mathrm{ppm}$ to $49-50 \mathrm{ppm}$. A similar dependence of the signal displacement upon the addition of various amines was observed during the earlier works [54,56]. Also, diethanolamino-modified materials PAF-20-G0, PAF-20-G1, PAF-30-G0 and PAF-30-G1 contained new signals at 56 and 58 ppm, which were assigned to carbon atoms of the ethanolamine groups.

Porous properties of PAFs were defined using low-temperature $\mathrm{N}_{2}$ adsorption. Starting materials PAF-20 and PAF-30 had $578 \mathrm{~m}^{2} / \mathrm{g}$ and $506 \mathrm{~m}^{2} / \mathrm{g}$ Brunauer-Emmett-Teller (BET) surface area, respectively (Table 1). The surface area of polymers decreased upon modification: after chloromethylation it was 472 and $436 \mathrm{~m}^{2} / \mathrm{g}$ for PAF-20-C $\mathrm{CH}_{2} \mathrm{Cl}$ and PAF-30- $\mathrm{CH}_{2} \mathrm{Cl}$, and after treatment with diethanolamine it was 64 and $31 \mathrm{~m}^{2} / \mathrm{g}$, respectively. Transition from G0 to G1 generation resulted in an even greater reduction of surface area, which was explained by the blocking of pores by bulky functional groups. 


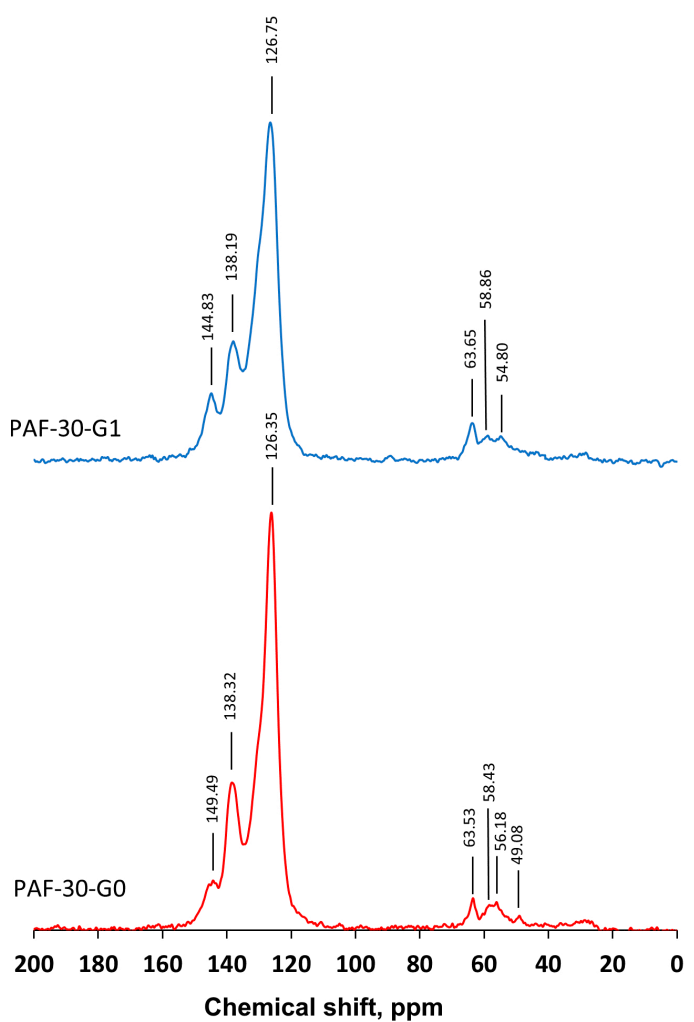

(a) 13C CP-MAS NMR for PAF-30-based materials

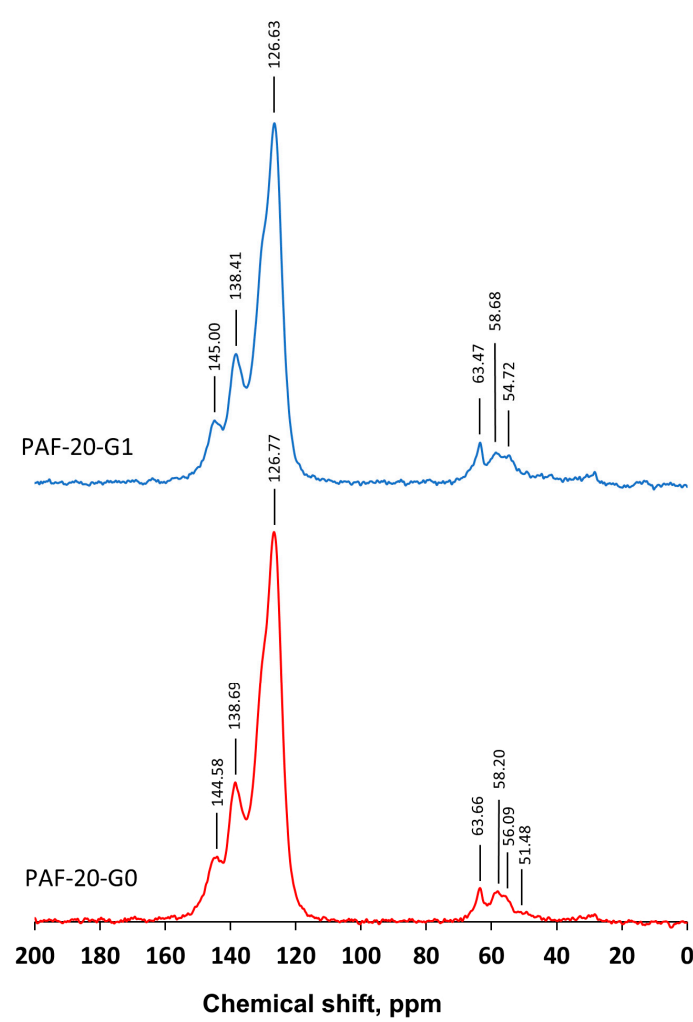

(b) 13C CP-MAS NMR for PAF-20-based materials

Figure 1. Solid-state 13C cross polarization-magic angle spinning nuclear magnetic resonance (CP-MAS NMR) spectra of obtained materials.

Table 1. Results of low-temperature nitrogen adsorption-desorption for obtained materials.

\begin{tabular}{ccccc}
\hline \multirow{2}{*}{ Samples } & \multicolumn{2}{c}{ Materials Based on PAF-20 } & \multicolumn{2}{c}{ Materials Based on PAF-30 } \\
\cline { 2 - 5 } & $\mathbf{S}_{\mathrm{BET}, \mathbf{~}^{2} / \mathbf{g}}$ & Total Pore Volume $\mathbf{( B J H )}, \mathbf{c m}^{\mathbf{3}} / \mathbf{g}$ & $\mathbf{S}_{\mathrm{BET}, \mathbf{m}^{2} / \mathbf{g}}$ & Total Pore Volume $\mathbf{( B J H )}, \mathbf{c m}^{\mathbf{3}} / \mathbf{g}$ \\
\hline PAF & 579 & 0.316 & 506 & 0.311 \\
PAF-CH ${ }_{2} \mathrm{Cl}$ & 472 & 0.264 & 436 & 0.262 \\
PAF-G0 & 29 & 0.026 & 61 & 0.054 \\
PAF-G1 & 5 & 0.001 & 38 & 0.007 \\
\hline
\end{tabular}

The adsorption isotherms (Figure 2) of the samples PAF-20 and PAF-30, as well as their chloromethylated derivatives, exhibited a sharp absorption of $\mathrm{N}_{2}$ at a low relative pressure $\left(\mathrm{p} / \mathrm{p}_{0}<0.05\right)$, which indicated the developed microporous structure of these materials. The presence of a hysteresis loop, and the fact that the nitrogen sorption curve gradually rose without the appearance of a plateau, may indicate the presence of mesopores in the polymer structure [58]. Conversely, this species may be due to diffusion restrictions or polymer swelling [59]. Chloromethylation did not change the character of nitrogen adsorption, which may indicate a uniform distribution of $-\mathrm{CH}_{2} \mathrm{Cl}$ groups over the volume of the carrier and a slight change in the pore size. 


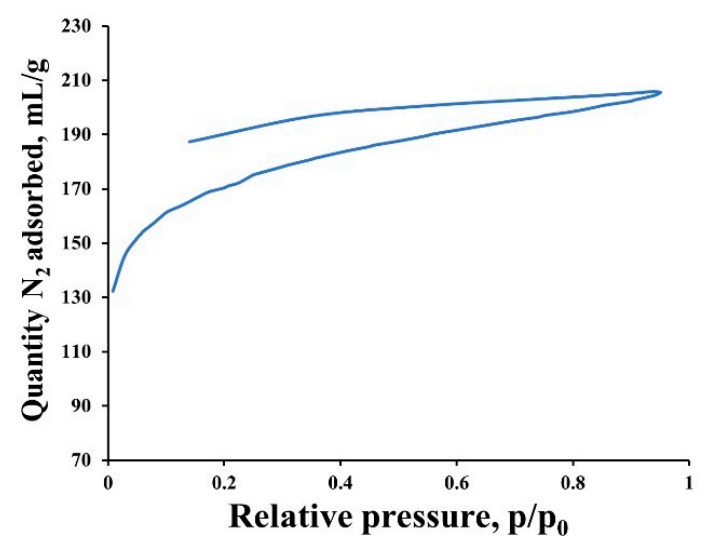

(a) $\mathrm{N}_{2}$ sorption on PAF-20

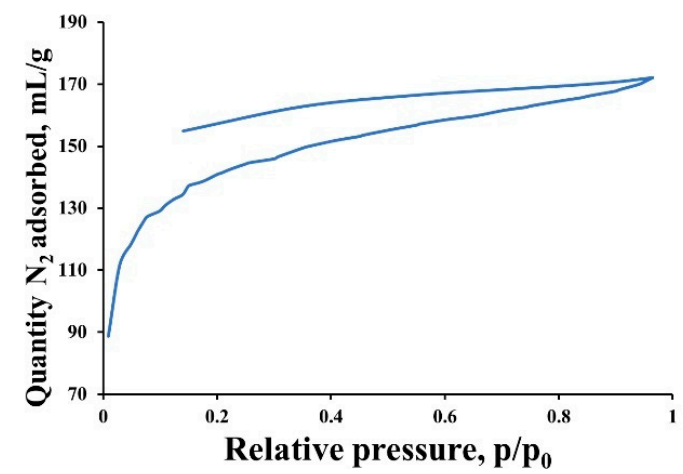

(c) $\mathrm{N}_{2}$ sorption on PAF-20-CH $\mathrm{C}_{2} \mathrm{Cl}$

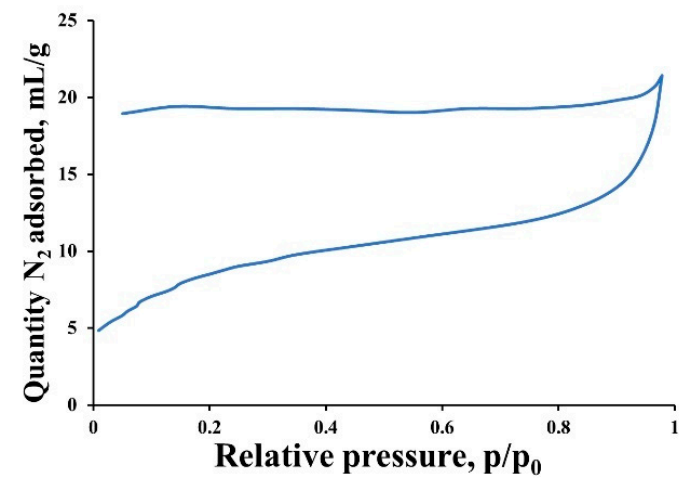

(e) $\mathrm{N}_{2}$ sorption on PAF-20-G0

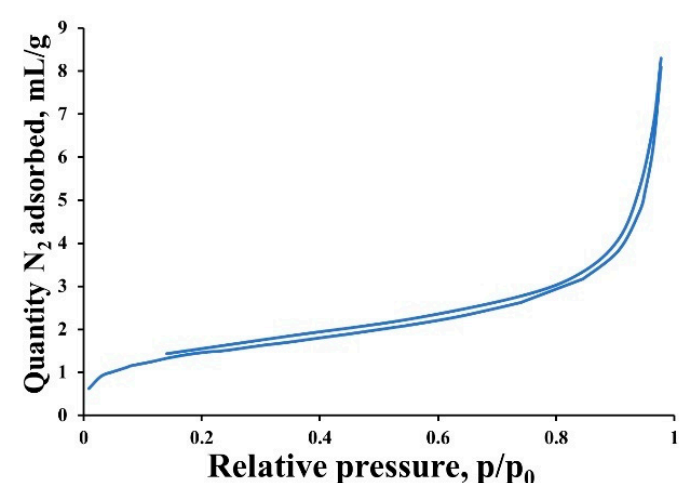

(g) N2 sorption on PAF-20-G1

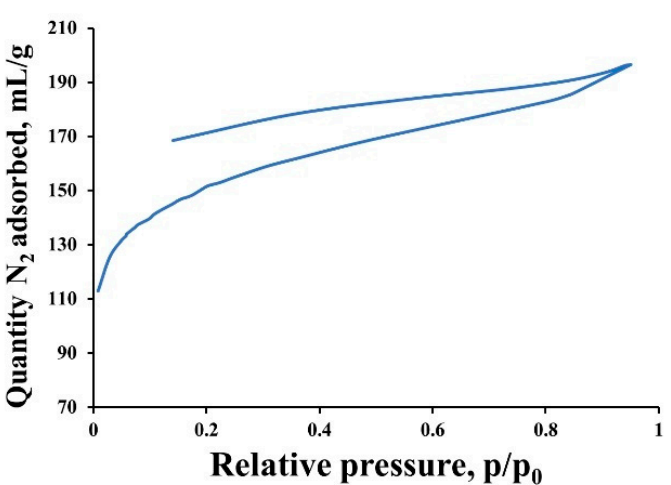

(b) $\mathrm{N}_{2}$ sorption on PAF-30

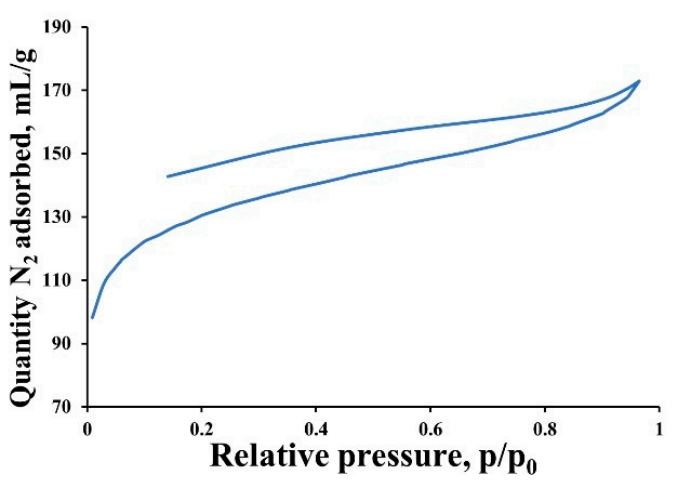

(d) $\mathrm{N}_{2}$ sorption on PAF-30- $\mathrm{CH}_{2} \mathrm{Cl}$

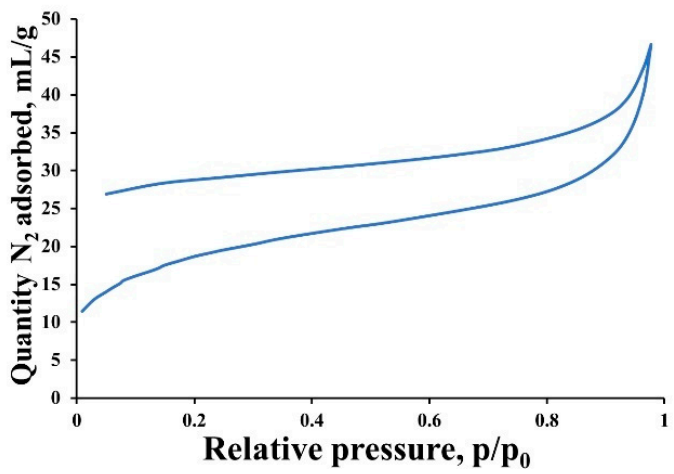

(f) $\mathrm{N}_{2}$ sorption on PAF-30-G0

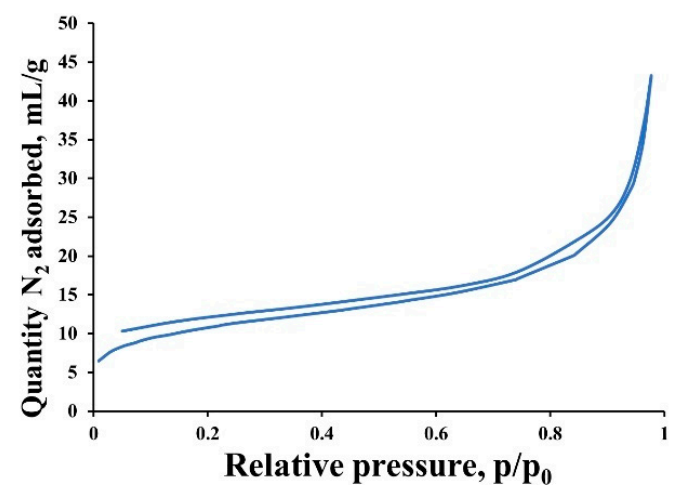

(h) $\mathrm{N}_{2}$ sorption on PAF-30-G1

Figure 2. Low-temperature $\mathrm{N}_{2}$ adsorption on PAF-based materials. 
Treatment of chloromethylated polymers with diethanolamine led to significant change in the character of nitrogen adsorption: there was no longer a sharp rise in the adsorption curve and, in the case of PAF-20-G0, there was practically no desorption of nitrogen from the pores. This shape of the curves can be associated with strong blocking of the pores by the diethanolamino-groups, which was more pronounced for PAF-20-G0 due to its smaller pore size. Further modification of materials up to generation G1 led to a further reduction in pore size: adsorption curves for PAF-20-G1 and PAF-30-G1 were typical for non-porous materials [58]. Thus, we can conclude for PAF-20-G0 and PAF-30-G0 materials, only a small fraction of the pores were available and. in the case of PAF-20-G1 and PAF-30-G1, the only pores available were in the immediate vicinity of the outer surface of the catalyst grain. Also, the decrease in surface area and porosity after grafting of the surface of porous materials is a well-known fact. Thus, after modification of PAFs with different polyamines [58], the surface area and free volume of pores decreased dramatically from $4023 \mathrm{~m}^{2} / \mathrm{g}$ for PPN-6 material to $555 \mathrm{~m}^{2} / \mathrm{g}$ for tris-(2-aminoethyl)amine-modified material. However, we should note that in the case of the modification of porous aromatic frameworks with diethanolamine led to too high a decrease in porosity.

Elemental analysis also suggests successful functionalization of aromatic rings with different functional groups (Table 2). The averaged content of chlorine in the materials PAF-20- $\mathrm{CH}_{2} \mathrm{Cl}$ and PAF-30- $\mathrm{CH}_{2} \mathrm{Cl}$ was $3 \%$ - to be exact, about $7 \%$ of the benzene rings were modified. After treatment of chloromethylated polymers with diethanolamine, it decreased to $0.9 \%-1.2 \%$, whereas nitrogen content in the resulting samples was $1.7 \%-1.8 \%$. The presence of chlorine in these samples may indicate an incomplete modification: most likely, chloromethyl groups deep into the catalyst grain did not react with diethanolamine. Regarding the materials of the G1 series, the content of chlorine was even higher, and the nitrogen content increased only slightly. It indicates the occurrence of the substitution reaction of the hydroxyl groups for chlorine atoms during the treatment of materials of the G0 series with thionyl chloride, on the one hand. The completeness of this reaction was even lower than in the synthesis of materials of the G0 series, on the other hand.

Table 2. Elemental analysis of synthesized materials.

\begin{tabular}{|c|c|c|}
\hline \multirow{2}{*}{ Material } & \multicolumn{2}{|c|}{ Element Content, Mass. \% } \\
\hline & $\mathrm{Cl}$ & $N$ \\
\hline PAF-20- $\mathrm{CH}_{2} \mathrm{Cl}$ & $3.08 \%$ & - \\
\hline PAF-30- $\mathrm{CH}_{2} \mathrm{Cl}$ & $3.00 \%$ & - \\
\hline PAF-20-G0 & $0.91 \%$ & $1.84 \%$ \\
\hline PAF-30-G0 & $1.19 \%$ & $1.68 \%$ \\
\hline PAF-20-G1 & $2.43 \%$ & $1.88 \%$ \\
\hline PAF-30-G1 & $3.30 \%$ & $2.16 \%$ \\
\hline
\end{tabular}

\subsection{Characterization of Palladium Catalysts}

Catalysts based on porous aromatic frameworks modified with the ethanolamine groups Pd-PAF-20-G0, Pd-PAF-20-G1, Pd-PAF-30-G0 and Pd-PAF-30-G1 were obtained by immobilizing palladium nanoparticles into pores of supports. The palladium content was determined by atomic absorption spectroscopy (AAS) (Table 3).

Pd-PAF-20-G0 and Pd-PAF-30-G0 catalysts contained well-dispersed small particles with a relatively narrow size distribution $(2-2.5 \mathrm{~nm}$ ) based on the transmission electron microscopy (TEM) microphotographs (Figure 3). This confirms the successful introduction of nanoparticles into the modified pores of materials.

Table 3. Palladium content by atomic absorption spectroscopy in synthesized catalysts.

\begin{tabular}{ccccc}
\hline Material & Pd-PAF-20-G0 & Pd-PAF-30-G0 & Pd-PAF-20-G1 & Pd-PAF-30-G1 \\
\hline Pd, mass $\%$ & 2.4 & 1.0 & 0.6 & 1.8 \\
\hline
\end{tabular}




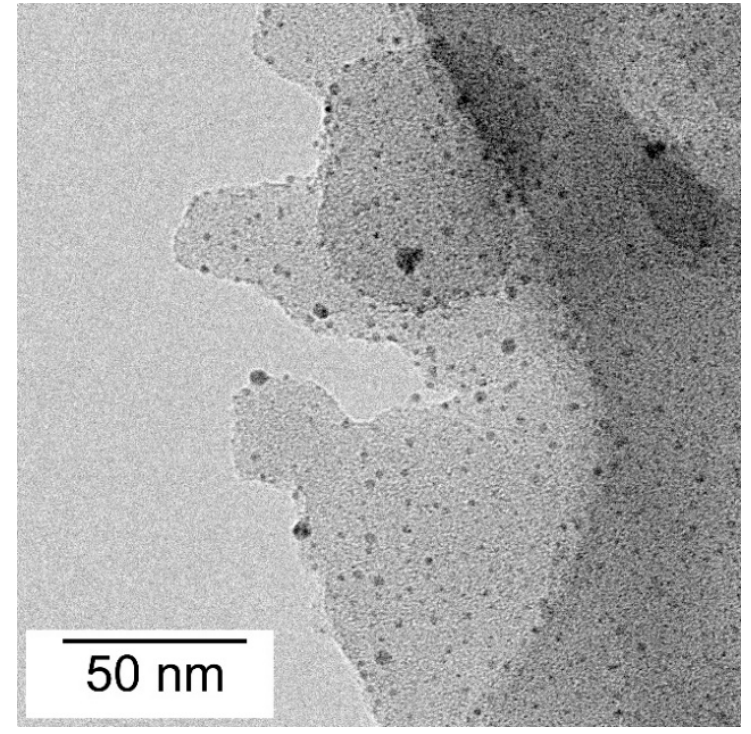

(a) TEM photograph of Pd-PAF-30-G0

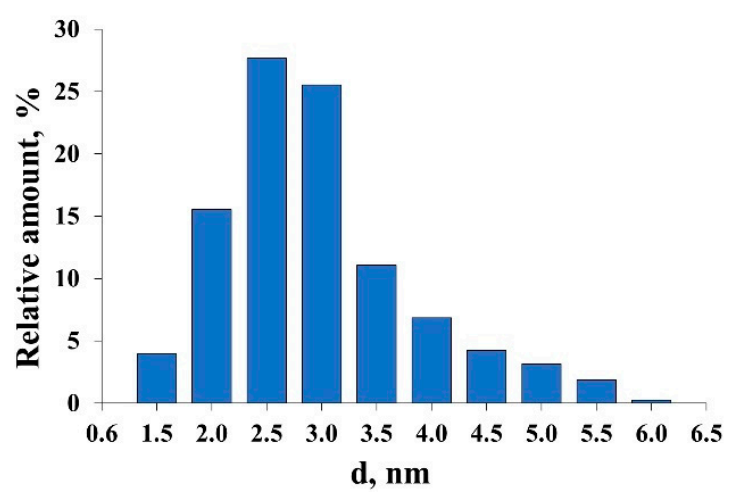

(c) particle size distribution for Pd-PAF-30-G0

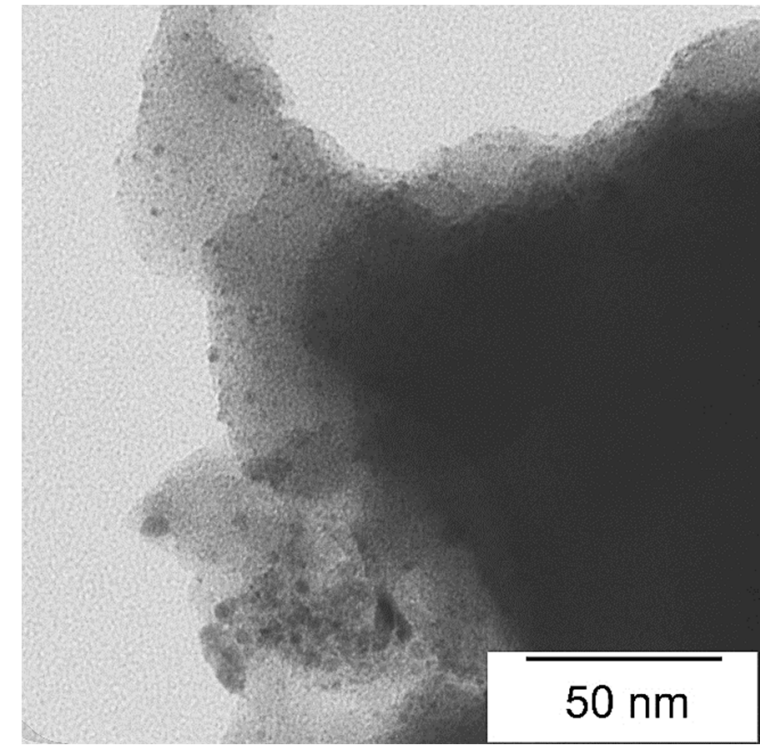

(b) TEM photograph of Pd-PAF-20-G0

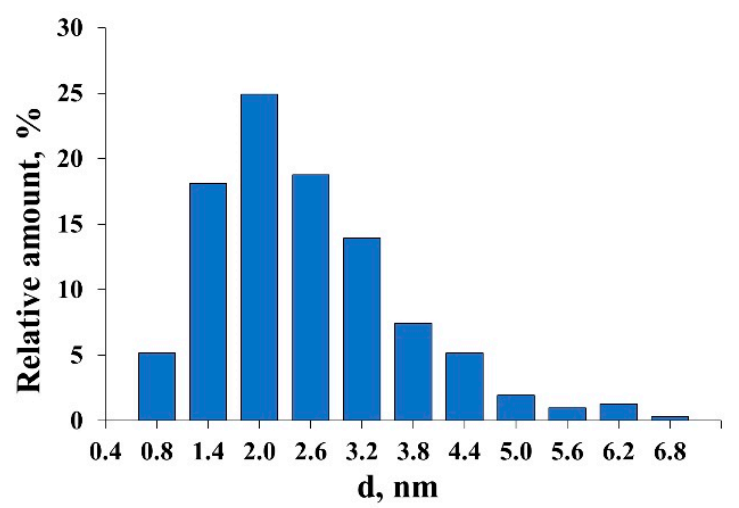

(d) particle size distribution for Pd-PAF-20-G0

Figure 3. Transmission electron microscopy microphotographs and particle size distribution for Pd-PAF-20-G0 and Pd-PAF-30-G0.

To contrast, the G1 series catalysts contained only a small number of palladium particles, which were larger (average size 7-8 nm) and the size distribution curves were wider (Figure 4 ). It is seen in the micrographs that there are few nanoparticles and agglomerates are observed on the surface. This fact may be due to the blocking of the pores by the diethanolamine groups, which interfere with the diffusion of palladium ions inside the porous structure. 


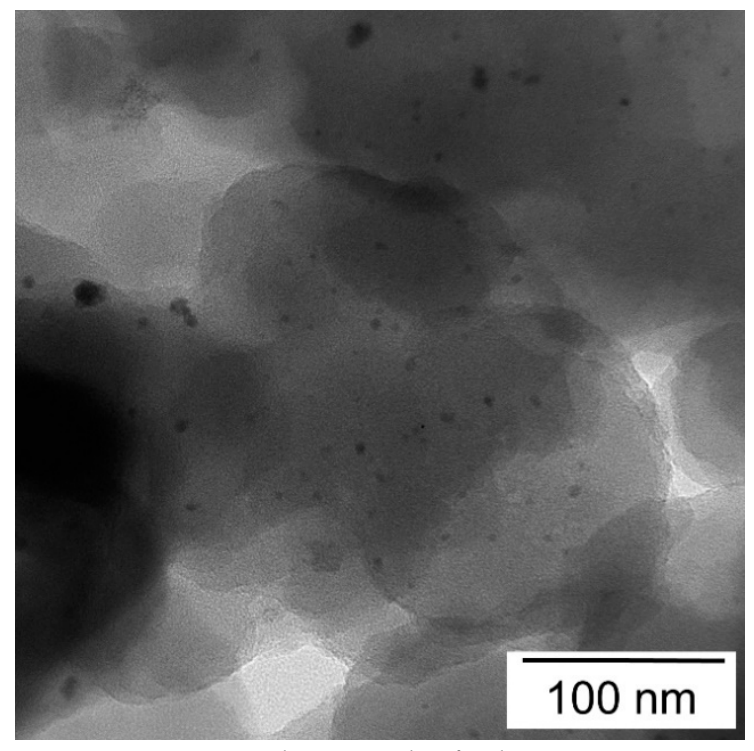

(a) TEM photograph of Pd-PAF-30-G1

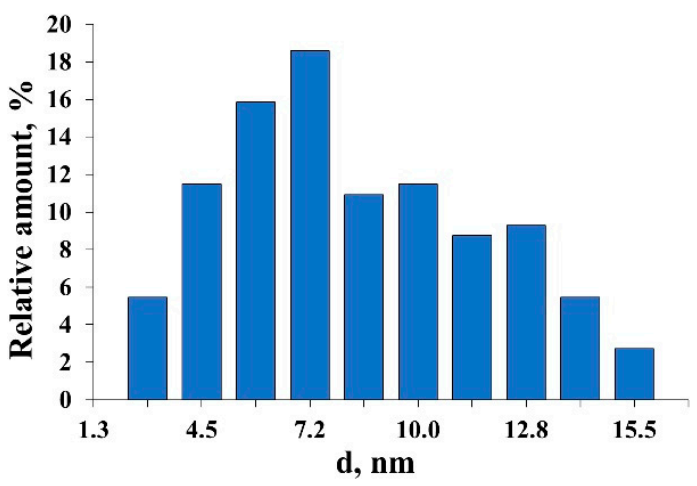

(c) particle size distribution for Pd-PAF-30-G1

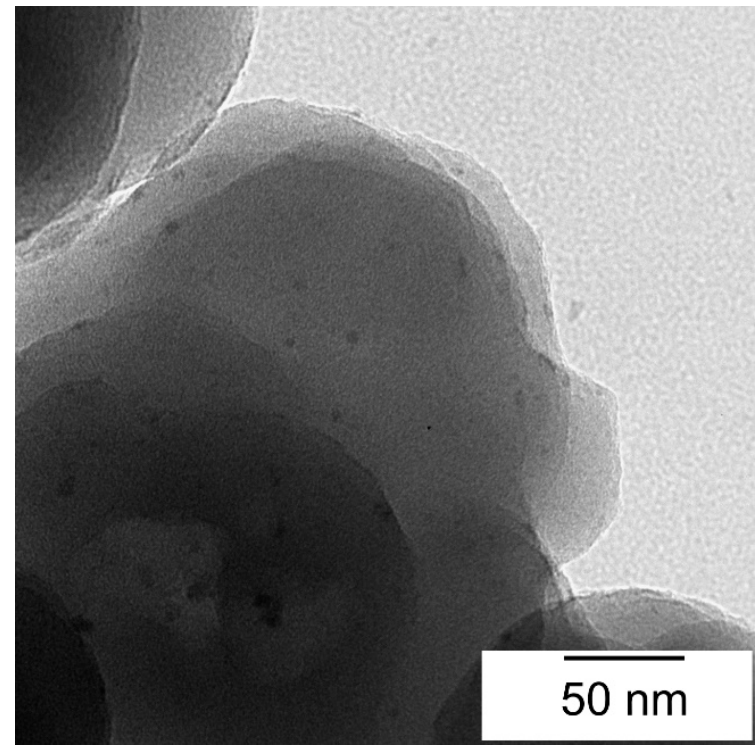

(b) TEM photograph of Pd-PAF-20-G1

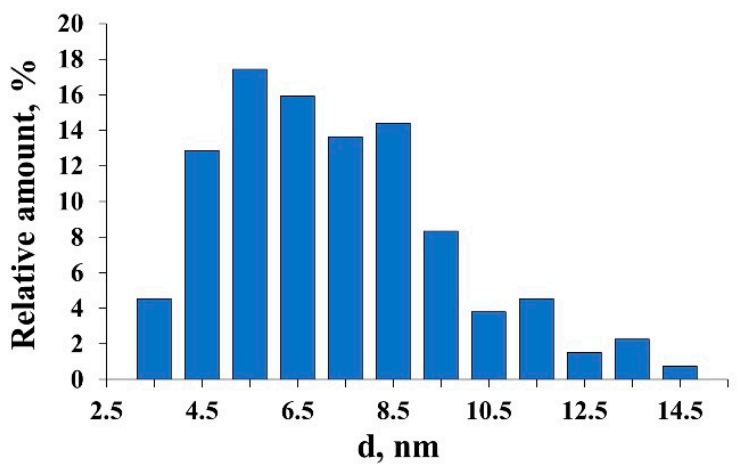

(d) particle size distribution for Pd-PAF-20-G1

Figure 4. TEM microphotographs and particle size distribution for Pd-PAF-20-G1 and Pd-PAF-30-G1.

According to the X-ray photoelectron spectroscopy (XPS) data (Table 4), the nitrogen content was higher in the materials of the $\mathrm{G} 1$ series, which proves the process of modification of ethanolamine groups during the synthesis of materials PAF-20-G1 and PAF-30-G0. Concurrently, the chlorine content in the materials with modification of the G1 type remained higher than in the G0 series. That demonstrates the incomplete reaction of the substitution of chlorine for diethanolamine at the last stage of synthesis. The palladium content was higher in materials of the G0 series, which may be due to better immobilization of the palladium particles in the pores of the support.

Table 4. Components of the XPS spectra.

\begin{tabular}{cccccc}
\hline Catalysts & $\mathbf{C}$ & $\mathbf{O}$ & $\mathbf{N}$ & $\mathbf{P d}$ & $\mathbf{C l}$ \\
\hline Pd-PAF-20-G0 & 82.2 at. $\%$ & 13.3 at. $\%$ & 1.5 at. $\%$ & 2.8 at. $\%$ & 0.1 at. $\%$ \\
Pd-PAF-30-G0 & 85.6 at. $\%$ & 11.2 at. $\%$ & 1.7 at. $\%$ & 1.3 at. $\%$ & 0.2 at. $\%$ \\
Pd-PAF-20-G1 & 87.9 at. $\%$ & 6.8 at. $\%$ & 3.4 at. $\%$ & 0.3 at. $\%$ & 0.6 at. $\%$ \\
Pd-PAF-30-G1 & 87.0 at. $\%$ & 9.2 at. $\%$ & 3.0 at. $\%$ & 0.3 at. $\%$ & 0.5 at. $\%$ \\
\hline
\end{tabular}

All XPS spectra demonstrated two sets of peaks related to reduced $\left(\mathrm{Pd}^{0}\right)$ and oxidized (PdOx) palladium forms (Figure 5). The presence of oxides in the spectra of samples could be due to incomplete reduction of the initial palladium or oxidation of the nanoparticles with atmospheric oxygen. The binding energies of $\mathrm{Pd}^{0} 3 \mathrm{~d}_{5 / 2}$ and $\mathrm{Pd}^{0} 3 \mathrm{~d}_{3 / 2}$ for Pd-PAF-20-G0 and Pd-PAF-30-G0 catalysts 
were higher than that for free $\mathrm{Pd}^{0}$ ( 335.6 and $341.1 \mathrm{eV}$, respectively). The changing of energy values indicates the presence of a coordination effect between nitrogen or oxygen atoms in the supports (Table 5). The same binding energies for the materials Pd-PAF-20-G1 and Pd-PAF-30-G1 were practically no different from the binding energies for free palladium. These results confirm the assumption that there is no coordination between palladium nanoparticles and the diethanolamine groups. Nanoparticles in these catalysts are either in unmodified pores or on the surface of the support.

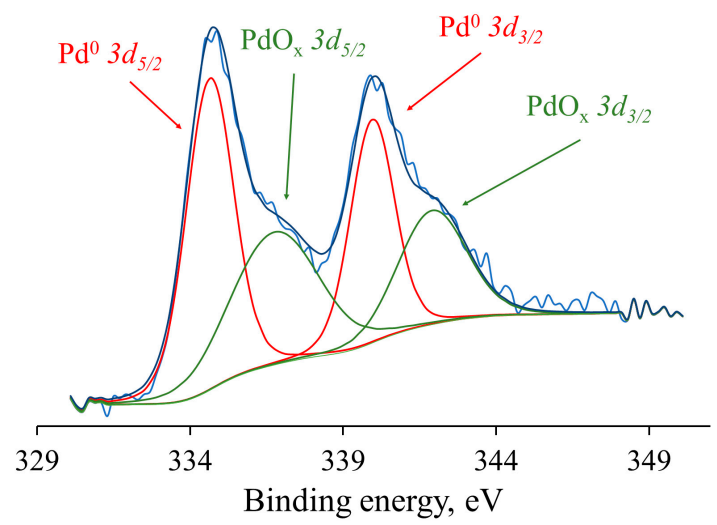

(a) XPS spectra of Pd 3d line in Pd-PAF-30-G0

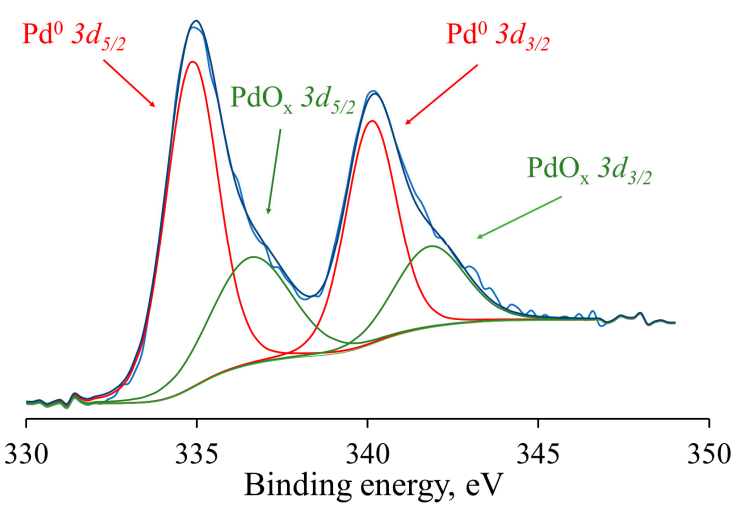

(c) XPS spectra of Pd 3d line in Pd-PAF-20-G0

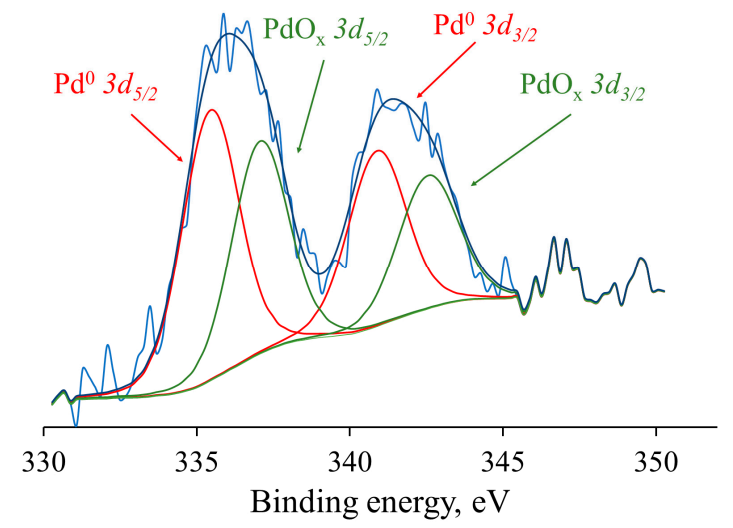

(b) XPS spectra of Pd 3d line in Pd-PAF-30-G1

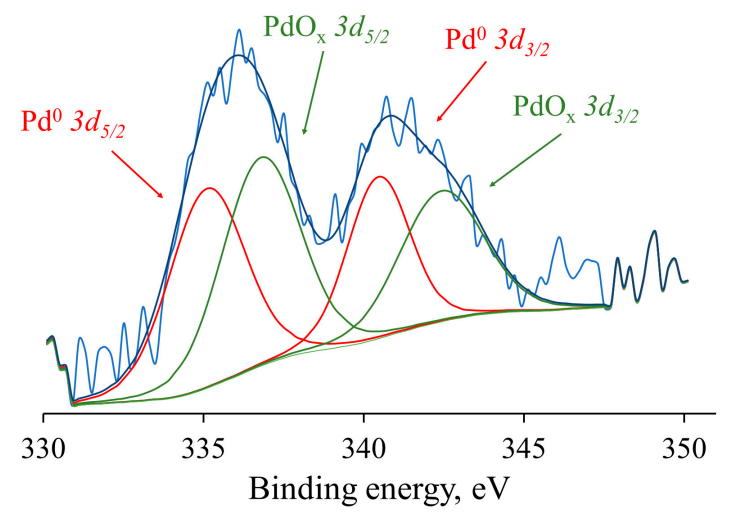

(d) XPS spectra of Pd 3d line in Pd-PAF-20-G1

Figure 5. X-ray photoelectron spectroscopy (XPS) measurements for obtained palladium catalysts.

Table 5. Peak parameters for XPS spectra of obtained palladium catalysts.

\begin{tabular}{|c|c|c|c|}
\hline Catalyst & Parameter & $\mathrm{Pd}^{0}$ & $\mathrm{PdO}_{\mathrm{x}}$ \\
\hline Pd-PAF-20-G0 & $\begin{array}{c}\text { Binding energy, eV } \\
\text { Content, \% }\end{array}$ & $\begin{array}{c}{\operatorname{Pd~} 3 d_{5 / 2}} 334.85 \mathrm{eV} \\
{\operatorname{Pd~} 3 d_{3 / 2} 340.10 \mathrm{eV}}_{67}\end{array}$ & 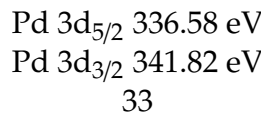 \\
\hline Pd-PAF-30-G0 & $\begin{array}{c}\text { Binding energy, eV } \\
\text { Content, \% }\end{array}$ & $\begin{array}{c}\mathrm{Pd} 3 \mathrm{~d}_{5 / 2} 334.65 \mathrm{eV} \\
{\mathrm{Pd} 3 \mathrm{~d}_{3 / 2} 339.96 \mathrm{eV}}_{56}\end{array}$ & $\begin{array}{c}\mathrm{Pd} 3 \mathrm{~d}_{5 / 2} 336.75 \mathrm{eV} \\
\mathrm{Pd} 3 \mathrm{~d}_{3 / 2} 341.91 \mathrm{eV} \\
44\end{array}$ \\
\hline Pd-PAF-20-G1 & $\begin{array}{c}\text { Binding energy, eV } \\
\text { Content, } \%\end{array}$ & 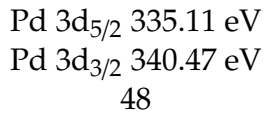 & 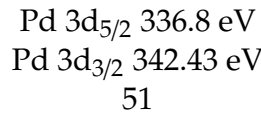 \\
\hline Pd-PAF-30-G1 & $\begin{array}{c}\text { Binding energy, eV } \\
\text { Content, \% }\end{array}$ & $\begin{array}{c}{\mathrm{Pd} 3 \mathrm{~d}_{5 / 2}} 335.45 \mathrm{eV} \\
\mathrm{Pd} 3 \mathrm{~d}_{3 / 2} 340.89 \mathrm{eV} \\
56\end{array}$ & 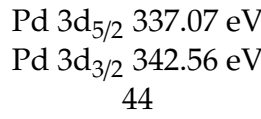 \\
\hline
\end{tabular}




\subsection{Catalytic Activity}

The synthesized catalysts were examined in the hydrogenation of various $C_{6}$ and $C_{8}$ unsaturated compounds (Table 6). The G0 series catalysts were more active than the G1 series catalysts, and catalysts based on the materials of the PAF-30 type were more active than those of the PAF-20 type. Thus, the Pd-PAF-30-G0 catalyst showed the highest activity in the hydrogenation of linear alkynes and alkenes: its specific activity (Table 7) was more than $300,000 \mathrm{~mol}$ sub $\times \mathrm{mol}_{\mathrm{Me}}{ }^{-1} \times \mathrm{h}^{-1}$ in the case of hexyne-1, hexene-1, octyne-1, and octene-1 (Table 7). Regarding 2,5-dimethyl-2,4-hexadiene, it was about $295,000 \mathrm{~mol}$ Sub $\times \mathrm{mol} \mathrm{Me}^{-1} \times \mathrm{h}^{-1}$ and, for more bulky substrates-phenylacetylene and

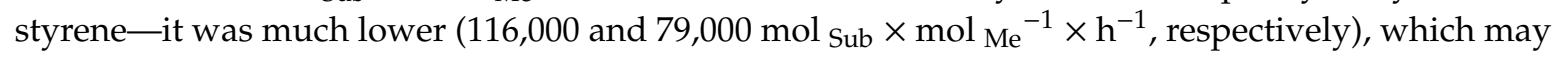
be due to conjugation between the benzene ring and double and triple bonds in these substrates.

Table 6. Hydrogenation of unsaturated hydrocarbons on palladium catalysts.

\begin{tabular}{cccccc}
\hline \multirow{2}{*}{ Substrate } & Reaction Products & \multicolumn{4}{c}{ Product Yield, $\%$} \\
\cline { 3 - 5 } & & Pd-PAF-20-G0 & Pd-PAF-30-G0 & Pd-PAF-20-G1 & Pd-PAF-30-G1 \\
\hline \multirow{2}{*}{ Hexyne-1 } & Hexene-1 & 85 & 94 & 9 & 35 \\
Hexene-1 & Hexane & 4 & 6 & - & - \\
Cyclohexene & Hexane & 34 & 100 & $<1$ & $<1$ \\
1,3-cyclohexadiene & Cyclohexane & 11 & 12 & - & - \\
Octyne-1 & Cyclohexadiene & 7 & 9 & - & - \\
Octyne-4 & Octene-1 & 6 & 99 & - & - \\
Octene-1 & Octene-4 & 3 & 4 & - & 1 \\
& Octane & 7 & 99 & $<1$ & 5 \\
2,5-dimethyl- & Isomerization products & 85 & $<1$ & 5 & $<$ \\
2,4-hexadiene & 2,5-dimethyl-3-hexene & 8 & 5 & $<1$ & - \\
Phenylacetylene & 2,5-dimethylhexane & $<1$ & 5 & $<1$ & - \\
Styrene & 2,5imethyl-2-hexene & 18 & 82 & - & - \\
4-methoxystyrene & Etyrene & 21 & 37 & - & - \\
\hline
\end{tabular}

Reaction conditions: $1 \mathrm{mg}$ of the catalyst; substrate:metal = 22,500:1 (Pd-PAF-20-G0), 54,000:1 (Pd-PAF-20-G1), 90,000:1 (Pd-PAF-30-G0), 30,000:1 (Pd-PAF-30-G1), $80{ }^{\circ} \mathrm{C}, 1.0 \mathrm{MPa} \mathrm{H}_{2}, 30 \mathrm{~min}$.

Table 7. Specific activity of synthesized catalysts.

\begin{tabular}{ccccc}
\hline Substrate & Pd-PAF-20-G0 & Pd-PAF-30-G0 & Pd-PAF-20-G1 & Pd-PAF-30-G1 \\
\hline Hexyne-1 & 94,600 & 323,400 & 100,700 & 189,800 \\
Hexene-1 & 34,600 & 305,100 & - & - \\
Cyclohexene & 11,200 & 36,600 & - & - \\
1,3-cyclohexadiene & 7100 & 27,400 & & - \\
Octyne-1 & 7100 & 302,000 & - & - \\
Octyne-4 & 5600 & 12,200 & & - \\
Octene-1 & 7100 & 305,100 & - & - \\
2,5-dimethyl-2,4-hexadiene & 27,500 & 294,900 & - & - \\
Phenylacetylene & 22,400 & 115,900 & - & \\
Styrene & 10,200 & 79,300 & - & \\
4-methoxystyrene & 5600 & 12,200 & & \\
\hline
\end{tabular}

Pd-PAF-20-G0 possessed lesser hydrogenation activity: high conversion was achieved only for hexyne-1, whereas yields of hydrogenation products for other substrates were much lower. This could be due to the smaller pore size in PAF-20 and, as a consequence, lower diffusion of substrates to palladium nanoparticles [33]. Catalysts Pd-PAF-20-G1 and Pd-PAF-30-G1 showed less activity. This may be due to the fact that further modification of the material with diethanolamine groups leads to a significant decrease in pore size, restricting the penetration of substrates, and the leaching of metal particles from the surface.

The stability of Pd-PAF-20-G0 and Pd-PAF-30-G0 catalysts was tested in recycle experiments regarding the hydrogenation of hexene-1. Both catalysts remained active for five reuse cycles. A slight reduction in conversions was observed only in the first two repetitions (Table 8). This fact is associated with the leaching of particles from the surface of the catalyst, as is seen in TEM micrographs, as well as 
in losses during catalytic experiments. A slight increase in the average particle size from 2.5 to $2.6 \mathrm{~nm}$ for Pd-PAF-30-G0, and from 2 to $2.9 \mathrm{~nm}$ for Pd-PAF-20-G0, can be noted; however, the distribution of the nanoparticles in the materials remained uniform (Figure 6). The washing out of nanoparticles from the surface also is confirmed by XPS data, according to which, after five reuse cycles, the amount of surface palladium decreased from 2.8 at. $\%$ to 2.1 at. $\%$ for Pd-PAF-20-G0, and from 1.3 at. $\%$ to 1.0 at. $\%$ for Pd PAF 30 G0 (Table 9).

Table 8. Results of recyclability tests.

\begin{tabular}{cccccc}
\hline \multirow{2}{*}{ Catalyst } & \multicolumn{5}{c}{ Product Yield, \% } \\
\cline { 2 - 6 } & Cycle 1 & Cycle 2 & Cycle 3 & Cycle 4 & Cycle 5 \\
\hline Pd-PAF-20-G0 & 34 & 28 & 16 & 16 & 17 \\
Pd-PAF-30-G0 & 99 & 98 & 86 & 84 & 83 \\
\hline
\end{tabular}

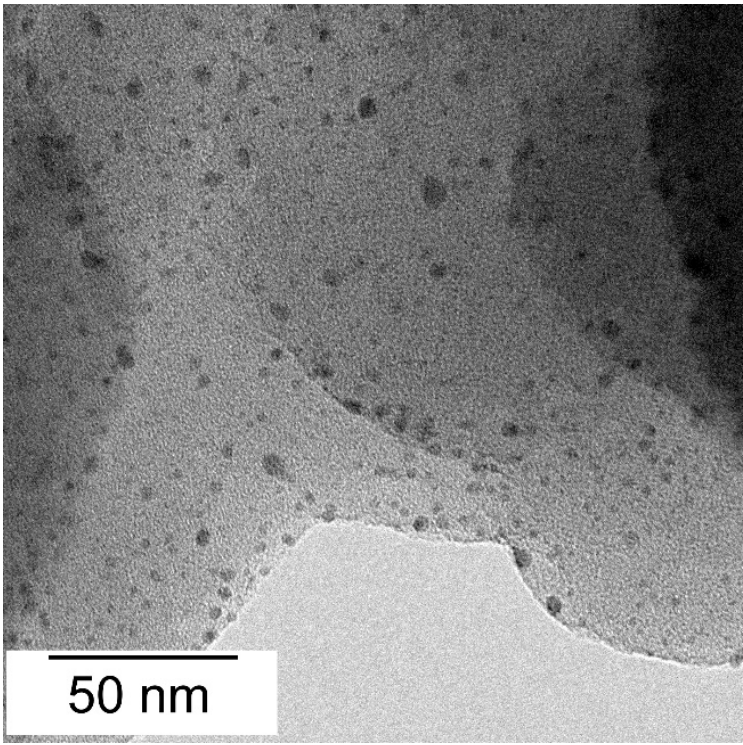

(a) TEM photograph of Pd-PAF-30-G0

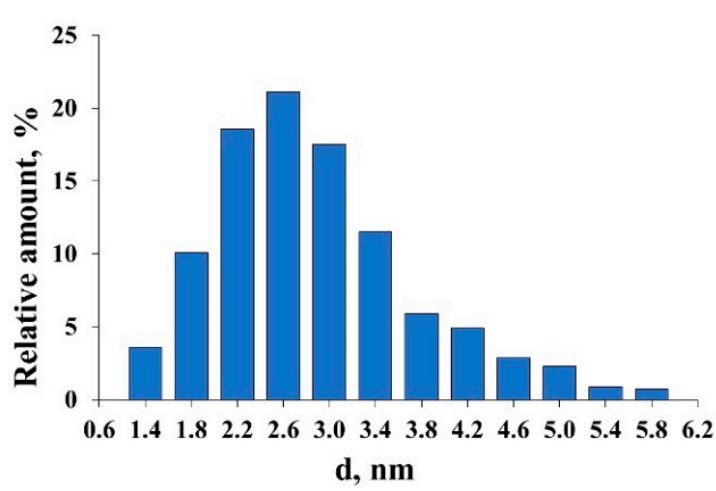

(c) particle size distribution for Pd-PAF-30-G0

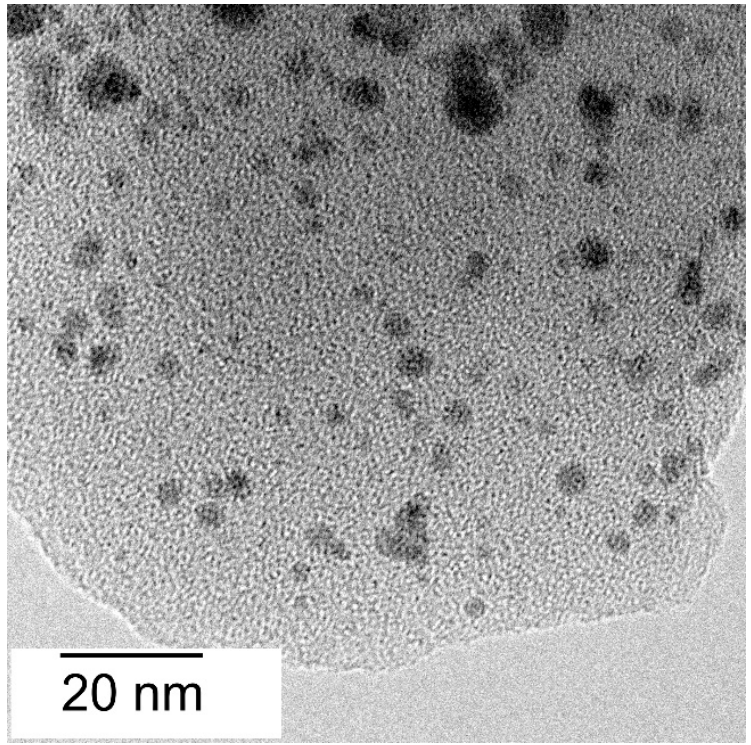

(b) TEM photograph of Pd-PAF-20-G0

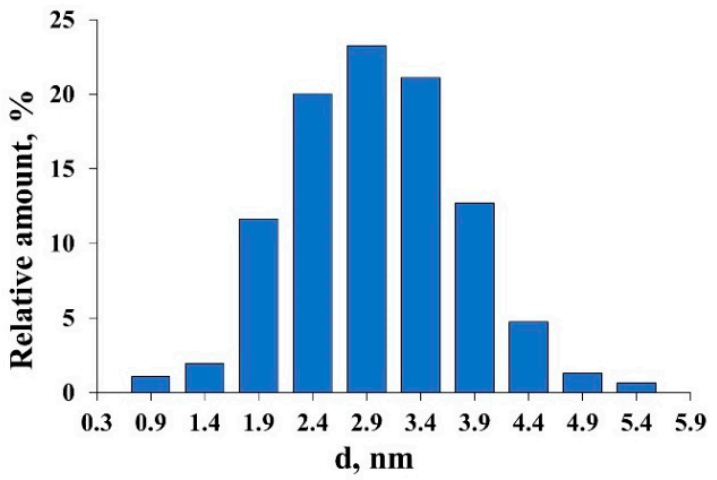

(d) particle size distribution for Pd-PAF-20-G0

Figure 6. TEM microphotographs and particle size distribution for Pd-PAF-20-G0 and Pd-PAF-30-G0 after five runs of the recycle process. 
Table 9. Components of the XPS spectra after five runs of the recycle process.

\begin{tabular}{|c|c|c|c|c|c|c|}
\hline \multicolumn{2}{|c|}{ Sample } & C & $\mathbf{O}$ & $\mathbf{N}$ & $\mathrm{Cl}$ & Pd \\
\hline \multirow{2}{*}{ Pd-PAF-20-G0 } & Before reaction & 82.2 at. $\%$ & 13.3 at. $\%$ & 1.5 at. $\%$ & 0.1 at. $\%$ & 2.8 at. $\%$ \\
\hline & After 5 runs & 79.4 at. $\%$ & 16.1 at. $\%$ & 2.1 at. $\%$ & 0.2 at. $\%$ & 2.1 at. $\%$ \\
\hline \multirow{2}{*}{ Pd-PAF-30-G0 } & Before reaction & 85.6 at. $\%$ & 11.2 at. $\%$ & 1.7 at. $\%$ & 0.2 at. $\%$ & 1.3 at. $\%$ \\
\hline & After 5 runs & 85.6 at. $\%$ & 12.3 at. $\%$ & 0.9 at. $\%$ & 0.2 at. $\%$ & 1.0 at. $\%$ \\
\hline
\end{tabular}

\section{Materials and Methods}

\subsection{Used Reagents}

The following reagents were used in the work: benzene (IREA 2000, Moscow, Russia, Purum p.a.); styrene (Aldrich, St. Louis, MO, USA, $\geq 99 \%$ ); phenylacetylene (Aldrich, Shanghai, China, 98\%); 2,5-dimethyl-2,4-hexadiene (Aldrich, St. Louis, MO, USA, 98\%); methanol (Acros Organics, Morris Plains, NJ, USA ); ethanol (IREA 2000, Moscow, Russia, Purum p.a.); chloroform (Ecos-1, Moscow, Russia, Purum), octene-1 (Aldrich, St. Louis, MO, USA, 98\%); octyne-1 (abcr, Karlsruhe, Germany, 98\%); 2,5-dimethylhexadiene-2,4 (Aldrich, St. Louis, MO, USA, 96\%), hexene-1 (Aldrich, St. Louis, MO, USA, 98\%), hexyne-1 (Aldrich, St. Louis, MO, USA, 99\%), 1,3-cyclohexadiene (Acros Organics, Morris Plains, NJ, USA), paraformaldehyde (Sigma-Aldrich, St. Louis, MO, USA, 95\%), hydrochloric acid (Sigma-tech, Moscow region, Russia, high-purity grade), phosphorus oxide(V) (Khimmed, Moscow, high-purity grade), acetic acid (Ruskhim, Moscow, Russia, high-purity grade), 1,4-dioxane (Ruskhim, Moscow, Russia, high-purity grade), diethanolamine (Sigma-Aldrich, St. Louis, MO, USA, 98\%), potassium iodide (Reakhim, Staraya Kupavna, Moscow region, Russia, high-purity grade), acetone (Ekros, Saint-Peterburg, Russia, high-purity grade) thionyl chloride (Sigma-Aldrich, St. Louis, MO, USA, 97\%), nitric acid (Component-Reaktiv, Moscow, Russia, high-purity grade), potassium carbonate (Component-reactive, Moscow, Russia, pure), sodium borohydride (Aldrich, St. Louis, MO, USA, $98 \%$ ).

PAFs ware prepared according to published literature procedures [53]. The modification techniques for PAF-20 and PAF-30 are similar. Below are the methods for modifying the PAF-20 material.

\subsection{Synthesis of PAF-20-CH}

Chloromethylation was carried out according to the method modified from a previous work [55]. Paraformaldehyde $(1 \mathrm{~g})$ and hydrochloric acid $(20 \mathrm{~mL})$ were placed in a round-bottomed flask equipped with a stirrer and a reflux condenser. After dissolving of paraformaldehyde, phosphorus pentoxide $(4 \mathrm{~g})$ and glacial acetic acid $(6 \mathrm{~mL})$ were carefully added to the mixture. Subsequently, PAF-20 (200 mg) was placed in the flask and stirred at $90{ }^{\circ} \mathrm{C}$ for 3 days. The resulting solid was collected using filtration, washed 3 times with water $(100 \mathrm{~mL})$ and ethanol $(100 \mathrm{~mL})$, and dried in vacuo to produce PAF-20- $\mathrm{CH}_{2} \mathrm{Cl}$ as a yellow powder.

\subsection{Synthesis of PAF-20-G0}

Modification of PAF-20- $\mathrm{CH}_{2} \mathrm{Cl}$ was performed according to the procedure adapted from a previous work [54]. PAF-20- $\mathrm{CH}_{2} \mathrm{Cl}(100 \mathrm{mg})$, dioxane $(6 \mathrm{~mL})$, diethanolamine $(0.4 \mathrm{~mL})$ and catalytic amounts of potassium iodide $(10 \mathrm{mg})$ were mixed in a round-bottomed flask and stirred at $70{ }^{\circ} \mathrm{C}$ for 3 days. The solid was collected using filtration, washed with acetone $(3 \times 50 \mathrm{~mL})$, and dried in vacuo. The obtained material, PAF-20- $\mathrm{CH}_{2} \mathrm{~N}\left(\mathrm{CH}_{2} \mathrm{CH}_{2} \mathrm{OH}\right)_{2}$, was called PAF-20-G0 as an analogy with the numbering of the dendrimer generations.

\subsection{Synthesis of PAF-20-G1}

PAF-20-G0 (100 mg) was mixed with 1,4-dioxane $(6 \mathrm{~mL})$ in a round-bottomed flask, and then thionyl chloride $(1.0 \mathrm{~mL})$ was added dropwise to the suspension. The resulting mixture was stirred at $80^{\circ} \mathrm{C}$ for $24 \mathrm{~h}$, then the solid was collected using filtration and washed with ethanol $(3 \times 50 \mathrm{~mL})$, a $2 \mathrm{M}$ 
solution of potassium carbonate $(3 \times 50 \mathrm{~mL})$, water $(3 \times 50 \mathrm{~mL})$ and ethanol $(3 \times 50 \mathrm{~mL})$, and dried in vacuo. Then, the resulting material PAF-20- $\mathrm{CH}_{2} \mathrm{~N}\left(\mathrm{CH}_{2} \mathrm{CH}_{2} \mathrm{Cl}\right)_{2}$, called PAF-20-G0.5, was placed in a round-bottomed flask with dioxane $(6 \mathrm{~mL})$, diethanolamine $(0.8 \mathrm{~mL})$ and potassium iodide $(10 \mathrm{mg})$. The suspension was stirred at $70{ }^{\circ} \mathrm{C}$ for 3 days. The resulting material was filtered off, washed with acetone $(3 \times 50 \mathrm{~mL})$ and dried in vacuo.

\subsection{Synthesis of Catalyst Pd-PAF-G0 and Pd-PAF-G1}

Immobilization of palladium particles into the pores of PAFs was performed by the method described by Karakhanov, E.A. et al. [16]. The synthesis procedure described below was used to prepare the catalysts Pd-PAF-20-G0, Pd-PAF-20-G1, Pd-PAF-30-G0 and Pd-PAF-30-G1. The procedure for the synthesis of catalyst Pd-PAF-20-G0 is an example.

Palladium acetate $(4.26 \mathrm{mg})$ was dissolved in chloroform $(6 \mathrm{~mL})$ in a round-bottomed flask, equipped with a magnetic stirrer and a reflux condenser. Then, PAF-20-G0 (100 mg) was added to the resulting solution. The suspension was stirred at $60{ }^{\circ} \mathrm{C}$ for $24 \mathrm{~h}$, and then a solution of sodium borohydride $(7 \mathrm{mg})$ in a water-ethanol mixture $(0.5 \mathrm{~mL}: 0.5 \mathrm{~mL})$ was added. The reaction mixture darkened and gas evolution was observed. Subsequently, the flask was closed with a stopper and left for $12 \mathrm{~h}$ with stirring. After the reaction, the resulting substance was collected by centrifugation, washed with water $(3 \times 50 \mathrm{~mL})$ and ethanol $(3 \times 50 \mathrm{~mL})$ to remove sodium tetraborate, the precipitate was isolated by centrifugation and dried in air.

\subsection{Catalytic Experiments}

The calculated amounts of substrates and catalyst $(1 \mathrm{mg})$ were placed in a glass tube equipped with a magnetic stirrer. The tube was placed in a steel autoclave, then it was sealed and pressurized with hydrogen at a pressure of $10 \mathrm{~atm}$. Reactions were carried out at $80^{\circ} \mathrm{C}$ for $30 \mathrm{~min}$. After completion of the reaction, the autoclave was cooled to room temperature and depressurized. Reaction products were analyzed by gas chromatography. Specific activity of the catalysts was calculated using following equation:

$$
\mathrm{A}=\frac{\mathrm{Conv} *(\mathrm{sub} / \mathrm{Me})}{\mathrm{D} * \mathrm{t}}
$$

where A is the specific activity, Conv is the conversion of the substrate, Sub/Me is the substrate to metal proportion, $\mathrm{D}$ is the metal dispersion, and $\mathrm{t}$ is the reaction time.

\subsection{Characterization}

\subsubsection{Low Temperature Nitrogen Adsorption}

Nitrogen desorption/desorption isotherms were recorded at $77 \mathrm{~K}$ with a Micromeritics Gemini VII 2390 instrument (Micromeritics, Norcross, GA, United States). All samples were degassed at $110{ }^{\circ} \mathrm{C}$ for $6 \mathrm{~h}$ before measurement. The surface area $\left(\mathrm{S}_{\mathrm{BET}}\right)$ was calculated using the Brunauer-Emmett-Teller (BET) method based on adsorption data in the relative pressure range $\mathrm{P} / \mathrm{P}_{0}=0.05-0.2$. The total pore volume (Vtot) was determined by the amount of nitrogen adsorbed at a relative pressure of $\mathrm{P} / \mathrm{P}_{0}=0.995$.

\subsubsection{Transmission Electron Microscopy (TEM)}

TEM analysis was carried out on a JEOL JEM-2100/Cs/GIF microscope (JEOL, Tokyo, Japan) with a $0.19 \mathrm{~nm}$ lattice fringe resolution and an accelerating voltage of $200 \mathrm{kV}$. The processing of the micrographs and the calculation of the average particle size were conducted using the ImageJ software program.

\subsubsection{X-ray Photoelectron Spectroscopy (XPS)}

XPS studies were performed on a VersaProbeII, ULVAC-PHI (ULVAC-PHI, Inc., Kanagawa, Japan) instrument using excitation with $\mathrm{Al} \mathrm{K} \alpha$ X-ray radiation at $1486.6 \mathrm{eV}$. The calibration of photoelectron 
peaks was based on the $\mathrm{Au} 4 \mathrm{f}$ line with a binding energy of $84 \mathrm{eV}$ and on the $\mathrm{Cu} 2 \mathrm{p} 3 / 2$ line $(932.6 \mathrm{eV})$. The transmission energy of the energy analyzer was $117.4 \mathrm{eV}$ (survey scans) and $23.5 \mathrm{eV}$ (individual lines).

\subsubsection{Gas-Liquid Chromatography}

Analysis of the reaction mixture was carried out on a Agilent 6890 G1530A chromatograph (Hewlett Packard, Santa-Clara, CA, United States) equipped with a flame-ionization detector and a HP-1 column ( $50 \mathrm{~m} \times 0.32 \mathrm{~mm} \times 1.05 \mu \mathrm{m}, 100 \%$ dimethylpolysiloxane grafted phase). Helium was a carrier gas; the analysis was carried out in constant pressure mode (1.53 bar). Chromatograms were recorded and analyzed on a computer using the HP ChemStation Rev.A.06.01 (403) software.

\subsubsection{Atomic Absorption Spectroscopy}

The Pd content in the catalysts was determined via atomic absorption spectroscopy (AAS) on an iCE 3000 Series AA spectrometer (Thermo Scientific, Santa-Clara, CA, United States) with flame atomization. The data were processed using the SOLAAR software.

\section{Conclusions}

To conclude, we developed active and selective catalysts based on hybrid materials. It was shown that introduction of ethanolamine groups allowed for achievement of an efficient sorption of palladium ions and uniform distribution of palladium nanoparticles in size and in the pores of the carrier. Catalysts based on PAF-20-G0 and PAF-30-G0 materials demonstrated a high catalytic activity and stability. Nanoparticles in these catalysts were located both on the surface of the support and in the pore space.

Modification of the G1 type led to blockage of the pores of the aromatic framework, which prevented the diffusion of palladium ions into the pores of the carrier. The G1 series catalysts contained larger particles (average size $7-8 \mathrm{~nm}$ ) and were characterized by a broader size distribution, and most of the nanoparticles were located on the material surface. The activity of the Pd-PAF-20-G1 and Pd-PAF-30-G1 catalysts turned out to be lower than that of the G0 series catalysts, which was due to the blockage of pores.

Thus, to enhance the activity of catalysts, it is necessary to solve the problem of a significant decrease in the porosity of hybrid materials, as well as to improve approaches to the modification of supports. Due to this, it will be possible to significantly expand the field of application of these materials, in particular, to use them to create catalysts for other catalytic processes (processing of petroleum fractions, bio-raw materials, fine organic synthesis, etc.)

Author Contributions: E.K., performed conceptualization; M.T., developed methodology; D.M., M.K., performed investigation; Y.K., performed formal analysis; A.M., performed supervision; L.K., performed writing. All authors have read and agreed to the published version of the manuscript.

Funding: This research was funded by RSF, grant number 20-19-00380.

Conflicts of Interest: The authors declare no conflict of interest.

\section{References}

1. Li, L.; Zhou, C.; Zhao, H.; Wang, R. Spatial control of palladium nanoparticles in flexible click-based porous organic polymers for hydrogenation of olefins and nitrobenzene. Nano Res. 2015, 8, 709-721. [CrossRef]

2. Li, L.; Zhao, H.; Wang, R. Tailorable synthesis of porous organic polymers decorating ultrafine palladium nanoparticles for hydrogenation of olefins. ACS Catal. 2015, 5, 948-955. [CrossRef]

3. Garg, G.; Foltran, S.; Favier, I.; Pla, D.; Medina-González, Y.; Gómez, M. Palladium nanoparticles stabilized by novel choline-based ionic liquids in glycerol applied in hydrogenation reactions. Catal. Today 2020, 346, 69-75. [CrossRef]

4. Chung, J.; Kim, C.; Jeong, H.; Yu, T.; Binh, D.H.; Jang, J.; Lee, J.; Kim, B.M.; Lim, B. Selective semihydrogenation of alkynes on shape-controlled palladium nanocrystals. Chem. Asian J. 2013, 8, 919-925. [CrossRef] [PubMed] 
5. Zhang, Y.; Riduan, S.N. Functional porous organic polymers for heterogeneous catalysis. Chem. Soc. Rev. 2012, 41, 2083-2094. [CrossRef]

6. Zhang, Q.; Yang, Y.; Zhang, S. Novel functionalized microporous organic networks based on triphenylphosphine. Chem. Eur. J. 2013, 19, 10024-10029. [CrossRef]

7. Hausoul, P.J.C.; Eggenhuisen, T.M.; Nand, D.; Baldus, M.; Weckhuysen, B.M.; Klein Gebbink, R.J.M.; Bruijnincx, P.C.A. Development of a 4,4'-biphenyl/phosphine-based COF for the heterogeneous Pd-catalysed telomerisation of 1,3-butadiene. Catal. Sci. Technol. 2013, 3, 2571-2579. [CrossRef]

8. Karakhanov, E.A.; Maksimov, A.L.; Zolotukhina, A.V.; Kardasheva, Y.S. Hydrogenation catalysts based on metal nanoparticles stabilized by organic ligands. Russ. Chem. Bull. 2013, 62, 1465-1492.

9. Karakhanov, E.; Maximov, A.; Kardasheva, Y.; Semernina, V.; Zolotukhina, A.; Ivanov, A.; Abbott, G.; Rosenberg, E.; Vinokurov, V. Pd nanoparticles in dendrimers immobilized on silica-polyamine composites as catalysts for selective hydrogenation. ACS Appl. Mater. Interfaces 2014, 6, 8807-8816. [CrossRef]

10. Karakhanov, E.A.; Maximov, A.L.; Zolotukhina, A.V. Selective semi-hydrogenation of phenyl acetylene by Pd nanocatalysts encapsulated into dendrimer networks. Mol. Catal. 2019, 469, 98-110. [CrossRef]

11. Chen, H.; He, Y.; Pfefferle, L.D.; Pu, W.; Wu, Y.; Qi, S. Phenol Catalytic Hydrogenation over Palladium Nanoparticles Supported on Metal-Organic Frameworks in the Aqueous Phase. ChemCatChem 2018, 10, 2558-2570. [CrossRef]

12. Jansen, J.F.G.A.; De Brabander-Van Den Berg, E.M.M.; Meijer, E.W. Encapsulation of guest molecules into a dendritic box. Science 1994, 266, 1226-1229. [CrossRef] [PubMed]

13. Niu, Y.; Crooks, R.M. Dendrimer-encapsulated metal nanoparticles and their applications to catalysis. C. R. Chim. 2003, 6, 1049-1059. [CrossRef]

14. Yates, C.R.; Hayes, W. Synthesis and applications of hyperbranched polymers. Eur. Polym. J. 2004, 40, $1257-1281$. [CrossRef]

15. Karakhanov, E.A.; Maximov, A.L.; Skorkin, V.A.; Zolotukhina, A.V.; Smerdov, A.S.; Tereshchenko, A.Y. Nanocatalysts based on dendrimers. Pure Appl. Chem. 2009, 81, 2013-2023. [CrossRef]

16. Karakhanov, E.A.; Maximov, A.L.; Zakharyan, E.M.; Zolotukhina, A.V.; Ivanov, A.O. Palladium nanoparticles on dendrimer-containing supports as catalysts for hydrogenation of unsaturated hydrocarbons. Mol. Catal. 2017, 440, 107-119. [CrossRef]

17. Karakanov, E.A.; Zolotukhina, A.V.; Ivanov, A.O.; Maximov, A.L. Dendrimer-Encapsulated Pd Nanoparticles, Immobilized in Silica Pores, as Catalysts for Selective Hydrogenation of Unsaturated Compounds. Chem. Open 2019, 8, 358-381. [CrossRef]

18. Krishnan, G.R.; Sreekumar, K. Synthesis and Characterization of Polystyrene Supported Catalytically Active Poly(amidoamine) Dendrimer-Palladium Nanoparticle Conjugates. Soft Mater. 2010, 8, 114-129. [CrossRef]

19. Alvarez, J.; Sun, L.; Crooks, R.M. Electroactive composite dendrimer films containing thiophene-terminated poly(amidoamine) dendrimers cross-linked by poly(3-methylthiophene). Chem. Mater. 2002, 14, 3995-4001. [CrossRef]

20. Murugan, E.; Rangasamy, R. Synthesis, characterization, and heterogeneous catalysis of polymer-supported poly(propyleneimine) dendrimer stabilized gold nanoparticle catalyst. J. Polym. Sci. Part A Polym. Chem. 2010, 48, 2525-2532. [CrossRef]

21. Li, L.; Zhao, H.; Wang, J.; Wang, R. Facile fabrication of ultrafine palladium nanoparticles with size- and location-control in click-based porous organic polymers. ACS Nano 2014, 8, 5352-5364.

22. Karakhanov, E.; Kardasheva, Y.; Kulikov, L.; Maximov, A.; Zolotukhina, A.; Vinnikova, M.; Ivanov, A. Sulfide catalysts supported on porous aromatic frameworks for naphthalene hydroprocessing. Catalysts 2016, 6, 1-11.

23. Yuan, Y.; Zhu, G. Porous Aromatic Frameworks as a Platform for Multifunctional Applications. ACS Cent. Sci. 2019, 5, 409-418. [PubMed]

24. Maximov, A.; Zolotukhina, A.; Kulikov, L.; Kardasheva, Y.; Karakhanov, E. Ruthenium catalysts based on mesoporous aromatic frameworks for the hydrogenation of arenes. React. Kinet. Mech. Catal. 2016, 117, 729-743.

25. Wang, F.; Mielby, J.; Richter, F.H.; Wang, G.; Prieto, G.; Kasama, T.; Weidenthaler, C.; Bongard, H.J.; Kegnæs, S.; Fürstner, A.; et al. A polyphenylene support for pd catalysts with exceptional catalytic activity. Angew. Chem. Int. Ed. 2014, 53, 8645-8648.

26. Kulikov, L.A.; Terenina, M.V.; Kryazheva, I.Y.; Karakhanov, E.A. Unsaturated-compound hydrogenation nanocatalysts based on palladium and platinum particles immobilized in pores of mesoporous aromatic frameworks. Pet. Chem. 2017, 57, 222-229. 
27. Su, J.; Chen, J.S. Synthetic porous materials applied in hydrogenation reactions. Microporous Mesoporous Mater. 2017, 237, 246-259.

28. Ben, T.; Ren, H.; Shengqian, M.; Cao, D.; Lan, J.; Jing, X.; Wang, W.; Xu, J.; Deng, F.; Simmons, J.M.; et al. Targeted synthesis of a porous aromatic framework with high stability and exceptionally high surface area. Angew. Chem. Int. Ed. 2009, 48, 9457-9460.

29. Garibay, S.J.; Weston, M.H.; Mondloch, J.E.; Colón, Y.J.; Farha, O.K.; Hupp, J.T.; Nguyen, S.T. Accessing functionalized porous aromatic frameworks (PAFs) through a de novo approach. CrystEngComm 2013, 15, 1515-1519.

30. Tian, Y.; Song, J.; Zhu, Y.; Zhao, H.; Muhammad, F.; Ma, T.; Chen, M.; Zhu, G. Understanding the desulphurization process in an ionic porous aromatic framework. Chem. Sci. 2019, 10, 606-613. [PubMed]

31. Vilian, A.T.E.; Puthiaraj, P.; Kwak, C.H.; Hwang, S.K.; Huh, Y.S.; Ahn, W.S.; Han, Y.K. Fabrication of Palladium Nanoparticles on Porous Aromatic Frameworks as a Sensing Platform to Detect Vanillin. ACS Appl. Mater. Interfaces 2016, 8, 12740-12747. [CrossRef] [PubMed]

32. Yang, Y.; Wang, T.; Jing, X.; Zhu, G. Phosphine-based porous aromatic frameworks for gold nanoparticle immobilization with superior catalytic activities. J. Mater. Chem. A 2019, 7, 10004-10009. [CrossRef]

33. Nikolaev, S.A.; Zanaveskin, L.N.; Smirnov, V.V.; Averyanov, V.A.; Zanaveskin, K.L. Catalytic hydrogenation of alkyne and alkadiene impurities from alkenes. Practical and theoretical aspects. Russ. Chem. Rev. 2009, 78, 231-247. [CrossRef]

34. Mallat, T.; Baiker, A. Selectivity enhancement in heterogeneous catalysis induced by reaction modifiers. Appl. Catal. A Gen. 2000, 200, 3-22. [CrossRef]

35. Xing, R.; Liu, Y.; Wu, H.; Li, X.; He, M.; Wu, P. Preparation of active and robust palladium nanoparticle catalysts stabilized by diamine-functionalized mesoporous polymers. Chem. Commun. 2008, 47, 6297-6299. [CrossRef]

36. Karakhanov, E.; Maximov, A.; Terenina, M.; Vinokurov, V.; Kulikov, L.; Makeeva, D.; Glotov, A. Selective hydrogenation of terminal alkynes over palladium nanoparticles within the pores of amino-modified porous aromatic frameworks. Catal. Today 2019. [CrossRef]

37. Verde-Sesto, E.; Merino, E.; Rangel-Rangel, E.; Corma, A.; Iglesias, M.; Sánchez, F. Postfunctionalized Porous Polymeric Aromatic Frameworks with an Organocatalyst and a Transition Metal Catalyst for Tandem Condensation-Hydrogenation Reactions. ACS Sustain. Chem. Eng. 2016, 4, 1078-1084. [CrossRef]

38. Li, L.; Chen, Z.; Zhong, H.; Wang, R. Urea-based porous organic frameworks: Effective supports for catalysis in neat water. Chem. Eur. J. 2014, 20, 3050-3060. [CrossRef]

39. Zhong, H.; Gong, Y.; Zhang, F.; Li, L.; Wang, R. Click-based porous organic framework containing chelating terdentate units and its application in hydrogenation of olefins. J. Mater. Chem. A 2014, 2, 7502-7508. [CrossRef]

40. Tang, D.; Sun, X.; Zhao, D.; Zhu, J.; Zhang, W.; Xu, X.; Zhao, Z. Nitrogen-Doped Carbon Xerogels Supporting Palladium Nanoparticles for Selective Hydrogenation Reactions: The Role of Pyridine Nitrogen Species. ChemCatChem 2018, 10, 1291-1299. [CrossRef]

41. Méry, D.; Astruc, D. Dendritic catalysis: Major concepts and recent progress. Coord. Chem. Rev. 2006, 250, 1965-1979. [CrossRef]

42. Lu, S.; Hu, Y.; Wan, S.; McCaffrey, R.; Jin, Y.; Gu, H.; Zhang, W. Synthesis of Ultrafine and Highly Dispersed Metal Nanoparticles Confined in a Thioether-Containing Covalent Organic Framework and Their Catalytic Applications. J. Am. Chem. Soc. 2017, 139, 17082-17088. [CrossRef] [PubMed]

43. Wang, Q.; Tsumori, N.; Kitta, M.; Xu, Q. Fast Dehydrogenation of Formic Acid over Palladium Nanoparticles Immobilized in Nitrogen-Doped Hierarchically Porous Carbon. ACS Catal. 2018, 8, 12041-12045. [CrossRef]

44. Neeli, C.K.P.; Puthiaraj, P.; Lee, Y.R.; Chung, Y.M.; Baeck, S.H.; Ahn, W.S. Transfer hydrogenation of nitrobenzene to aniline in water using Pd nanoparticles immobilized on amine-functionalized UiO-66. Catal. Today 2018, 303, 227-234. [CrossRef]

45. Sadjadi, S.; Koohestani, F. Pd immobilized on polymeric network containing imidazolium salt, cyclodextrin and carbon nanotubes: Efficient and recyclable catalyst for the hydrogenation of nitroarenes in aqueous media. J. Mol. Liq. 2020, 301, 112414. [CrossRef]

46. Zhou, S.; Shang, L.; Zhao, Y.; Shi, R.; Waterhouse, G.I.N.; Huang, Y.; Zheng, L.; Zhang, T. Pd Single-Atom Catalysts on Nitrogen-Doped Graphene for the Highly Selective Photothermal Hydrogenation of Acetylene to Ethylene. Adv. Mater. 2019, 31, 1900509. [CrossRef] 
47. Crooks, R.M.; Zhao, M.; Sun, L.; Chechik, V.; Yeung, L.K. Dendrimer-encapsulated metal nanoparticles: Synthesis, characterization, and applications to catalysis. Acc. Chem. Res. 2001, 34, 181-190. [CrossRef]

48. Boronoev, M.P.; Zolotukhina, A.V.; Ignatyeva, V.I.; Terenina, M.V.; Maximov, A.L.; Karakhanov, E.A. Palladium Catalysts Based on Mesoporous Organic Materials in Semihydrogenation of Alkynes. Macromol. Symp. 2016, 363, 57-63. [CrossRef]

49. King, A.S.H.; Twyman, L.J. Heterogeneous and solid supported dendrimer catalysts. J. Chem. Soc. Perkin 2002, 2, 2209-2218. [CrossRef]

50. Soğukömeroğulları, H.G.; Karataş, Y.; Celebi, M.; Gülcan, M.; Sönmez, M.; Zahmakiran, M. Palladium nanoparticles decorated on amine functionalized graphene nanosheets as excellent nanocatalyst for the hydrogenation of nitrophenols to aminophenol counterparts. J. Hazard. Mater. 2019, 369, 96-107. [CrossRef]

51. Yang, J.; Yuan, M.; Xu, D.; Zhao, H.; Zhu, Y.; Fan, M.; Zhang, F.; Dong, Z. Highly dispersed ultrafine palladium nanoparticles encapsulated in a triazinyl functionalized porous organic polymer as a highly efficient catalyst for transfer hydrogenation of aldehydes. J. Mater. Chem. A 2018, 6, 18242-18251. [CrossRef]

52. Xu, D.; Wang, F.; Yu, G.; Zhao, H.; Yang, J.; Yuan, M.; Zhang, X.; Dong, Z. Aminal-based Hypercrosslinked Polymer Modified with Small Palladium Nanoparticles for Efficiently Catalytic Reduction of Nitroarenes. ChemCatChem 2018, 10, 4569-4577. [CrossRef]

53. Yuan, Y.; Sun, F.; Ren, H.; Jing, X.; Wang, W.; Ma, H.; Zhao, H.; Zhu, G. Targeted synthesis of a porous aromatic framework with a high adsorption capacity for organic molecules. J. Mater. Chem. 2011, 21, 13498-13502. [CrossRef]

54. Gangadharan, D.; Dhandhala, N.; Dixit, D.; Thakur, R.S.; Popat, K.M.; Anand, P.S. Investigation of solid supported dendrimers for water disinfection. J. Appl. Polym. Sci. 2012, 124, 1384-1391. [CrossRef]

55. Lu, W.; Sculley, J.P.; Yuan, D.; Krishna, R.; Wei, Z.; Zhou, H.C. Polyamine-tethered porous polymer networks for carbon dioxide capture from flue gas. Angew. Chem. Int. Ed. 2012, 51, 7480-7484. [CrossRef]

56. Law, R.V.; Sherrington, D.C.; Snape, C.E.; Ando, I.; Korosu, H. Solid State 13C MAS NMR Studies of Anion Exchange Resins and Their Precursors. Ind. Eng. Chem. Res. 1995, 34, 2740-2749. [CrossRef]

57. Rangel-Rangel, E.; Verde-Sesto, E.; Rasero-Almansa, A.M.; Iglesias, M.; Sánchez, F. Porous aromatic frameworks (PAFs) as efficient supports for N-heterocyclic carbene catalysts. Catal. Sci. Technol. 2016, 6, 6037-6045. [CrossRef]

58. Thommes, M.; Kaneko, K.; Neimark, A.V.; Olivier, J.P.; Rodriguez-Reinoso, F.; Rouquerol, J.; Sing, K.S.W. Physisorption of gases, with special reference to the evaluation of surface area and pore size distribution (IUPAC Technical Report). Pure Appl. Chem. 2015, 87, 1051-1069. [CrossRef]

59. Jeromenok, J.; Weber, J. Restricted access: On the nature of adsorption/desorption hysteresis in amorphous, microporous polymeric materials. Langmuir 2013, 29, 12982-12989. [CrossRef] 